\title{
How accomplished are we for writing our national flora?
}

\author{
Potharaju Venu* and Munivenkatappa Sanjappa
}

This article deliberates upon expertise availability and material limitations which are considered as core hurdles in writing a comprehensive flora for India. The efforts carried out so far by the Botanical Survey of India and multiple and diverse technical impediments for permission to collect biological materials in Reserve Forests and other Protected Areas are detailed. Constraints to access type specimens and authenticated materials housed in European herbaria are elaborated. Digitization and database development to build an Indian virtual herbarium are to be taken up on priority basis for expeditious completion. Multinational collaborative projects promoting joint explorations/scrutiny of specimens/old literature/correspondence related to Indian flora would facilitate a full grasp and a clear presentation on the taxa reported from the country. This will boost the pace of publishing a national flora with the desired excellence.

Keywords: Herbaria, multilateral collaboration, national flora, taxonomic literature.

PLANT taxonomy essentially deals with the plant world, the diversity and the relationships therein through identification, naming, classification and thereby achieving the systematic documentation of plants. India's privileged location at the confluence of three key biogeographic realms, namely Indo-Malayan, Indo-Arctic (Eurasia) and Afro-tropical, bestows it with its own exclusivity as well with substantial commonality in floral content with neighbouring countries. Among the 35 biodiversity hotspots recognized by the Conservation International world over, four, viz. Indo-Burma (Assam, Manipur, Mizoram, Meghalaya, Nagaland, Tripura and Andaman Islands), the Himalaya (the Eastern Himalaya: parts of Nepal, Bhutan, the Indian states of West Bengal, Sikkim, part of Assam, and Arunachal Pradesh, part of Tibet (Autonomous Region of China, some parts of Pakistan and Afghanistan), and northern Myanmar; and the Western Himalaya: Kumaon-Garhwal, northwest Kashmir, and Afghanistan and northern Pakistan), the Western Ghats (parts of Kerala, Karnataka, Tamil Nadu, Goa, Maharashtra and Gujarat), and the Sundaland (the Nicobar Islands) spread across parts of India, and this is where the Indian flora is essentially concentrated and expectedly distinctive. About $28 \%$ of the Indian plants are endemic to the country. Hooker and his collaborators (1872-1890) in a seven-volume work on the flora of British India presented about 14,300 species (belonging to 171 families and 2325 genera) of

Potharaju Venu is in the Environment Protection Training and Research Institute, Gachibowli, Hyderabad 500 048, India; Munivenkatappa Sanjappa is in the Botanical Garden, University of Agricultural Sciences, GKVK Campus, Bengaluru 560 065, India.

*For correspondence. (e-mail: pvenu.bsi@gmail.com) flowering plants ${ }^{1}$. The British India, then intended for the work, comprised India, Pakistan, Afghanistan, Nepal, Tibet, Bangladesh, Myanmar (then Burma), Sri Lanka and the Malayan Peninsula. As many as 10,200 species (belonging to 170 families, 2070 genera) can be sorted out as exclusive to the present boundaries of India, or sharing their presence with the neighbouring countries. Provincial/regional floras which were published in the later years, have further added taxa for different phytogeographic regions ${ }^{2-7}$. These floras were executed with great diligence and clarity on individual taxa citing authenticated specimens in some of them (not in all floras), and also explicated ambiguities, if any, to be clarified/resolved. These floras along with The Flora of British India ${ }^{1}$ served well for general identification of specimens and for other taxonomic works till the end of the 20th century. A comprehensive flora was felt necessary for multiple reasons, and the Botanical Survey of India (BSI) (founded in 1890 and reorganized in 1954), holding many other responsibilities, had initiated the task of writing revised national flora while continuing surveys in unexplored and under-explored areas. The 12 regional centres of BSI spread nationwide in different phytogeographic regions with organized herbaria (housing over 3 million specimens, including over 19,000 types) and libraries possessing classical as well as the latest literature dealing with taxonomy and phytogeography. These centres together have extensive ex situ conservation facilities comprising 861 acres of gardens/ conventional conservatories with live plants of about 7050 species. BSI started publishing national flora initially in the form of fascicles (the first one was published in 1978 and there are totally 26 so far) and later simultaneously 
publishing in volumes (the first 3 were published in 1997); the Survey has so far published 11 volumes (including two introductory ones) out of 32 volumes envisaged under national flora. Thus a revised national flora remained a partly accomplished dream, similar to other major flora initiatives like Fl. N. America and Fl. Malesiana. Though some genera/tribes/families were subjected to serious revisionary scrutiny in the published volumes of national flora, some groups remained as mere compilations for want of type materials and expertise.

\section{Explorations and implications}

Explorations are an integral part of this floral documentation to gather diverse plant species and explorers cannot swab all the plant species in one go, as the seasonality of flowering/fruiting varies with species and also with general limitations of completing collections in a single attempt. Explorations remained a major activity in the reorganized BSI and about 100 organized field tours on an average get projected every year exploring many remote areas (and in particular Protected Areas (PAs)) of the country, thereby gathering materials for systematic documentation. Today our herbaria have more than 3 million specimens, as stated earlier.

\section{New species/new records/rare species}

Plant discoveries often happen when novelties are recognized from such gathered materials and reported/ published. These reports are welcomed with enthusiasm and excitement as they are supposed to stir/review all the known component species of the genus which they belong to for morphological similarities/differences, so as to recognize near similar/allied species and the novelty of the species under reference in reporting. The authors who contribute to such publications eternally remain as an authority to the taxon (species/infraspecific categories) published. The other outcomes of plant explorations, which are often ranked as of auxiliary significance, include collection of rare species after considerable time periods, and recognition of new records and additions for specific geographic areas, which are under exploration (not new to science but never reported before from the area concerned). The joy of collection of a rare species lies with not only looking at the living plant in its habitat, but getting an opportunity to work with live specimens to improve descriptions. Quite a few species (majorly endemic) reported from the Andaman and Nicobar Islands appear in unresolved status in important plant databases as they are represented by single/couple of collections often with no flowers, fruits or both, and often with poor/incomplete descriptions. Occasionally, these were treated as synonyms under different accepted names in different works. Additions/new records help in greater perception on the extent of geographical distribution of the species under consideration, its conservation status as well in evaluating commonalities of the flora in different phytogeographic regions. Several species earlier considered endemic to Sri Lanka are reported from the Southern Western Ghats as new records for India. All the three achievements are cherished by the taxonomists, and have diverse implications in floral documentation and consolidation.

\section{Disturbed areas and surveys}

There are disturbed areas in India, which include naxalinfested regions in parts Andhra Pradesh, Bihar, Chhattisgarh, Jharkhand, Karnataka, Kerala, Madhya Pradesh, Maharashtra, Odisha and West Bengal; insurgency issues in parts of North East India (Arunachal Pradesh, Assam, Meghalaya, Tripura, Mizoram, Manipur and Nagaland), and militancy in the Kashmir Valley. These areas remained underexplored by BSI for want of safety/security of the personnel involved in such explorations. Moreover, some of these areas are too remote to operate from the headquarters or from the regional centres of the survey. Such areas require to be covered and the best option is to seek local help through established institutions/ universities. If necessary, orientation training in collection activity may be given to these people and the focus should be entirely on material collection and support to the regional centres of BSI.

\section{Updating floral wealth}

With active explorations all around and continued reporting of new species, new records and extended distributions between states, the estimated figures for various groups have been changing every year. Since 2007, BSI has been compiling/consolidating information on plant discoveries annually and thereby updating the estimated taxa in every group. These figures might not qualify for actual/absolute numbers since some names got reduced as synonyms in various works and were not accounted for, but can be taken for near approximations for different groups. This is also due to lack of revisionary scrutiny of different taxonomic groups.

Keeping aside such a scrutiny, a 2016 report by $\mathrm{BSI}^{8}$ projected that India harboured about 18,465 species of seed plants $(18,386$ angiosperms +79 species of gymnosperms). It may be affirmed that our knowledge base on floral wealth of the country got truly augmented (compare the projected figure with the total documented species in The Flora of British India ${ }^{1}$ ). As a result, a comprehensive flora for the country was felt necessary not only to include such vast data, but for substantially different treatments (now assumed accurate) acquired through taxonomic and phylogenetic studies on many genera/families. 


\section{Issues in collection activity}

Inventories (both floral/faunal) prepared on mere visual sightings/evidences lack academic credibility. Forests are the focused areas for exploration and collection of biological materials. There exist technical impediments/glitches for collections and particularly permission for biological collections is not granted easily in Reserve Forests and other Protected Areas. Biodiversity Act/Rules, 2002/2004 imposes restrictions on foreigners and NRIs to collect and take material outside the country. The Act and the Rules detail the procedure for access to biological resources and associated traditional knowledge (Rule \#14), and restriction of activities related to endemic/endangered taxa (Rule \#16). These regulations and guidelines are relevant when there is large-scale harvesting of biological material for research or other commercial purposes. They have no relevance to taxonomic research where sampling is only minimal and handled by biodiversity specialists who are essentially sensitive to conservation. Such sampling poses no threat to any species. Since no concessions are provided for taxonomists or for taxonomic research, these guidelines and regulations apply equally on all taxonomists and create an impediment to international collaborative explorations. In such cases, the collaboration is approved if detailed MoUs are signed between the institutions and the project is approved by the Government of India. Further, forests are a state subject and permission for collection is vested with the State Forest Departments. In the near absence of any regulations and guidelines from Central/State Governments (these vary from State to State), forest authorities often impose their terms and conditions, which are arbitrary at times, in the process of granting permissions for collecting plant materials during explorations.

\section{Novelty syndrome/species proliferation}

Taxonomy is inherently complex and vast by nature. It can be easily complicated if handled without restraint/ caution in floral documentation. One should have adequate knowledge both in taxonomy and nomenclature while consolidating any group. Often the expertise with many taxonomists is either in taxonomy or nomenclature. New species reporting requires great prudence and sound knowledge of the genus concerned. A generalist will not be in a position to weigh novelty as knowledgeably as a specialist in specific groups. More often, subjectivity prevails in taxonomic decisions. Taxonomists in exploration should ensure that what they perceive as novelty is definable and consistent with variations in key traits of the group and visible consistently in multiple individuals of different populations and not as freaks which appear and disappear. Taxonomic revisions are essentially consolidation exercises of specific groups which view the group in its entirety of circumscription, diversity and its range of distribution. New species which are published with thoroughness will not wither in such exercises and receive universal acceptance as for characterization and identity (name) in the assigned group. Unfortunately, there are multiple instances where new species have been published without expected rigorous scrutiny of the materials/literature. Some of them not even survived but got reduced as synonyms of known species. Such publications often come from generalists and not from specialists of the group. The insensitive approach towards reporting of new species in pteridophytes was published by FraserJenkins 9 . Such a review for angiosperms is not available so far, but in fact warranted. These publications contributed little but as such generated great confusion in the group.

\section{Types and other authentic materials in European herbaria}

The taxonomic practices provide a procedure/method for naming, reporting (publishing) and subsequent cautious filing of type material in the herbarium. Protologues and type materials provide crucial data in establishing the identity of a given species. The type specimens and authenticated materials of many species described in The Flora of British India ${ }^{1}$ and to some extent in the subsequent regional floras are housed in European herbaria. Since types cannot be loaned easily, taxonomists require visiting these herbaria for such material study. Thanks to information technology, taxonomists now can access the digital images, but they are of limited use in critical cases. The Indian Botanical Liaison Officer posted at the Royal Botanic Garden, Kew, London, UK largely used to assist in getting images and herbarium label data associated with authentic as well as type specimens in at least herbaria in the UK. Unfortunately, for the past 6 years or so, no taxonomist has been deputed to work at Kew. In fact, this limited support from a single liaison officer is not enough as he/she gets engaged in the revision of a certain group as part of the assignment in this deputation.

\section{Failings in type deposition}

In protologue, everything associated with a name, including the citation of designated holotype is given by the author. The holotype, where the name gets permanently attached, stands as attestation for the future and facilitates for the plant to which, this name could be precisely applied to ensure stability in nomenclature. Failing in the deposition of types in designated herbaria or erroneous type citations leads to ambiguity and a debacle in revisionary works and consolidation of floras ${ }^{10}$. A verification exercise was undertaken to check whether the types of names of new taxa published in a few taxonomy journals 
between 1991 and 2004 are duly deposited in different herbaria cited in the protologues. Overall analysis suggested that $30-40 \%$ of published names have either no traceable holotypes in the herbaria cited in the protologues $^{11-14}$ or have erroneous type citations in the protologues. In the Melbourne code ${ }^{15}$, the names are considered not validly published if types are not indicated (Art. 40.1), but there is no provision to handle situations where types are cited but never deposited in the cited herbaria. Specialists who would be revising their specialized groups will face serious predicament in handling such situations. There will be further boom in the publication of new species in India with no holds bar, as Art. 29 of the Code permits electronic publication of new species as a PDF file in an online publication with an ISSN or ISBN (with effective date 1 January 2013) as valid. Most taxonomists are willingly or unwillingly ignorant of the requirements in the deposition of type and other authentic materials in designated national repositories according to the Biodiversity Act 2002 and Rules 2004. Little do they realize the damage caused by not depositing materials in identified repositories. Most are possessive to keep them in poorly maintained herbaria or in their personal custody, while others never want further scrutiny on their new species. Ultimately such required collections are either missed, destroyed or damaged, creating a serious problem in taxonomic decisions on the correct identity of plants. There are some who willingly and obligingly deposit type/authentic materials in herbaria/museums abroad without intimating the National Biodiversity Authority if new species/varieties proposed by them have been published in journals abroad.

\section{Multiple agendas}

With multiple agendas, BSI has compromised with its core mandate of writing the national flora mainly due to inadequate experienced taxonomists for various reasons. The Survey had fluctuated to work on lower groups through flagship programmes of AICOPTAX of the Ministry of Environment, Forests and Climate Change. Though these groups are no less important, this happened at the cost of diluting the focus on angiosperms which dominate in space than the lower groups. Secondly, manpower in BSI has continuously dwindled owing to nonrecruitment against the retired positions. There have been hardly any opportunities for BSI personnel to collaborate with well-reputed international herbaria to enhance their professional competency. Many of them have never experienced the nuances involved in handling serious revisionary works. The perceptions of several personnel have never gone beyond the publication of new species/new records. BSI has vacillated on state/district floras of little consequence. So far the Survey has published 45 volumes of 25 state floras and 34 volumes of 25 district floras, and many miscellaneous publications (on threatened/Red
Listed species for their ex situ conservation and conservation awareness; fragile ecosystems and PAs; chromosome studies; taxonomic studies including revisions and checklists; taxonomic studies on pteridophytes, bryophytes, lichens and fungi; accounts of special groups like insectivorous plants, poisonous plants, etc. and traditional knowledge documentation). Many of them do not serve the expected readership since they lack original descriptions with identical monotonous citations sometimes contradicting illustrations, and inconsistent and often unworkable identification keys. Further, there is no way to guess how many of them have vouchers cited/duly deposited and how much authenticity was added in the determinations of relevant deposited specimens. Such works barely support in building a national flora.

\section{Indian Virtual Herbarium}

Today, information on botanical collections is accessible through digitization, database development and internet connectivity. The building up of a comprehensive database of the Indian Virtual Herbarium is a priority goal for BSI. This is a database of dried plant specimens that maximizes the usefulness of the collections. Apart from scanned images of the herbarium specimens, the label data on each species get digitalized. JPEG image of herbarium specimens under high resolution with colour scale will help the users to identify the plant species. Users can browse species by barcode number, family, genus, collector and country. The website provides basic and advanced search capabilities. Text entered in basic search is searched in all fields of the herbarium database, while advanced search allows text to be searched in a specific field. A link of IPNI is provided, from which one can obtain publication details, basionym/s and accepted names. Digitization of type specimens (dicot: 14,900; monocot: 3,028 ) has been completed by the Central National Herbarium. Apart from this, many slack groups such as rare, endangered and threatened species (406 specimens), medicinal plants (3400 specimens), Rosaceae (1000 specimens) and Acanthaceae (11832 specimens) have been digitized.

\section{How to go about national flora?}

What is important is to envisage meaningful collaboration with the world's established taxonomic institutions/ specialists in various groups/families/genera. Generally, there will be a good deal of field visits/experts/herbarium consultations involved in writing a flora. Monographers and taxonomic revisioners can sort, detect and add authenticity in the determinations of these specimens. As mentioned, novelties go unnoticed when there is lack of expertise in specific groups, and the number of experts associated with Indian herbaria is not adequate to secure 
sufficiently qualified identification. The Flora Malesiana project that had aimed at the vascular flora of Malesiana (covering the biogeographical region of Indonesia, Malaysia, Singapore, Brunei, the Philippines and Papua New Guinea) could not be completed by the scientific efforts of some 100 collaborators from all over the world. The Flora of China project is an outstanding example of massive international collaboration between Chinese and non-Chinese (from 29 countries, mostly European and American) botanists to complete the flora consisting of an estimated 31,000 species of wild vascular plants in China. The project began in 1988 with a 21 -member editorial committee and 11 partner institutions, coordinated by the Missouri Botanical Garden, St. Louis, USA and the Institute of Botany, Chinese Academy of Sciences, Beijing, China. The flora written by about 450 authors comprises 25 volumes of text and 25 volumes of illustrations. Similarly, in 2000, the University of Karachi, Pakistan and the Missouri Botanical Garden signed an agreement to copublish the unfinished volumes of The Flora of Pakistan over a period of five years, which finally got finished. Similarly, The Flora of Sri Lanka (Revised Handbook of Flora of Ceylon), a collaborative effort of Sinhalese and American taxonomists initially and British taxonomists later completed the vascular flora.

To expedite the publication of a comprehensive national flora in India, we must collaborate with institutions such as the herbarium of the Royal Botanic Gardens, Kew; the Natural History Museum of London (formerly British Museum of Natural History); the Royal Botanic Garden of Edinburgh, and other European herbaria, as they have specialists for different taxonomic groups and equally crucial original collections based on which most of our floras were written during the colonial period. The Central National Herbarium (CAL) has volumes of correspondences and a number of manuscripts and botanical paintings/illustrations that date back to the establishment of the Botanic Garden at Calcutta in 1787. Their study has relevance to construct the botanical history of India with greater authenticity. It is worth noting that virtually a good portion of the collections, including types made in India before independence is housed in Europe (mainly BM (Natural History Museum [British Museum], UK; E (Royal Botanic Garden, Edinburgh) and K (Royal Botanic Gardens, Kew)) and not easily accessible to botanists in India. Joint explorations in all phytogeographic regions and the study of specimens of particularly difficult or poorly known taxonomic groups are to be encouraged and organized in order to understand tropical plant diversity in its totality. Writing a flora at the national level, and producing monographs of specific groups with worldwide syntheses are possible only through such collaborations. The team should include botanical artists and photographers, working with the focus towards user-friendly 'Flora of India, fully illustrated and updated'. If properly financed and supported, such international collaborations are bound to succeed, because the European and Indian herbaria have jointly built-up the collections, expertise, and historical and geographical data which are needed ${ }^{16}$. Honestly, if we continue with the expertise we have today, it may take quite a long time to complete our national flora, which the country can ill-afford.

1. Hooker, J. D., The Flora of British India, Vols 1-7, L. Reeve \& Co, London, 1872-1890.

2. Gamble, J. S., Flora of the Presidency of Madras, Vols 1-3, West, Newman and Adlard, London, 1915-1936.

3. Cooke, T., The Flora of the Presidency of Bombay, Vols 1-2, Taylor and Francis, London, 1903.

4. Prain, D., Bengal Plants. Vols 1-2, N W \& Company Printers \& Publishers, Calcutta, 1903.

5. Kanjilal, U. N. et al., Flora of Assam, Vols 1-6, Government of Assam, Gauhati, 1934-1940.

6. Duthie, J. F., Flora of the Upper Gangetic Plain and of the Adjacent Siwalik and Sub-Himalayan Tracts, Vols 1-2, Taylor and Francis, London, 1903.

7. Haines, H. H., The Botany of Bihar and Orissa, Vols 1-3, L. Reeve \& Co, London, 1922.

8. BSI, Plant Discoveries, Botanical Survey of India, Kolkata, 2016.

9. Fraser-Jenkins, C. R., New Species Syndrome in Indian Pteridology and the Ferns of Nepal, International Book Distributors, Dehra Dun, 1997.

10. Bandyopadhyay, S. et al., Are we following the Art. 40.7 of the Code in letter and spirit? Phytotaxa, 2014, 163(4), 239-240.

11. Bandyopadhyay, S. et al., Failings in holotype deposition of twelve plant names. Indian J. For., 2016, 39(4), 407.

12. Bandyopadhyay, S. et al., Names of new taxa published and types deposited - a case study. Ann. Plant Sci., 2016, 5(10), 1451-1457.

13. Bandyopadhyay, S. et al., Names of new taxa published and types deposited - a second case study. Ann. Plant Sci., 2017, 6, 15851589.

14. Bandyopadhyay, S. et al., Missing holotypes of names in plants, fungi and algae published from India. Int. J. Adv. Res. Bot., 2017, 3(3), 34-39.

15. McNeill, J. et al., International Code of Nomenclature for algae, fungi and plants (Melbourne Code) adopted by the Eighteenth International Botanical Congress, Melbourne, Australia, July 2011. Regnum Veg., 2012, 154, 1-140.

16. Sanjappa, M. and Venu, P., Indian herbaria: legacy, floristic documentation and issues of maintenance. Proceedings on Tropical plant collections legacies from the past? Essential tools for the Future? (eds Fries, I. and Balslev, H.), in The Royal Danish Academy of Sciences and Letters, Denmark, 2017, pp. 149-162.

Received 1 March 2018; revised accepted 7 February 2019

doi: $10.18520 / \mathrm{cs} / \mathrm{v} 116 / \mathrm{i} 8 / 1299-1303$ 